\title{
Safety of hyperbaric oxygen therapy in mechanically ventilated patients
}

\author{
Jacques Bessereau ${ }^{1,2}$, Jérôme Aboab ${ }^{1}$, Thomas Hullin ${ }^{1}$, Anne Huon-Bessereau ${ }^{1}$, \\ Jean-Luc Bourgeois ${ }^{3}$, Pierre-Marie Brun ${ }^{2}$, Sylvie Chevret ${ }^{4}$, Djillali Annane ${ }^{1}$ \\ ${ }^{1}$ Intensive Care Unit and Hyperbaric Department, CHU Raymond Poincaré, APHP, Garches, France \\ 2Pôle RUSH, SAMU13, CHU La Timone, APHM, Marseille, France \\ ${ }^{3}$ Department of Anaesthesiology, Clinique de l'Archette, Olivet, France \\ ${ }^{4}$ SBIM, URCC, CHU St-Louis, APHP, Paris, France
}

\begin{abstract}
Background: To evaluate the epidemiology of patients who require mechanical ventilation during hyperbaric oxygen therapy.

Materials and methods: One-hundred-fifty patients who required mechanical ventilation during hyperbaric oxygen therapy were prospectively studied during a 6-year period in a French university hyperbaric centre. We analysed the indication of hyperbaric oxygen therapy, agent used for sedation, presence of a chest tube, need for vasopressor agents and tolerance and appearance of side effects. Finally, we compared the outcomes of patients according to the presence or absence of acute respiratory distress syndrome (ARDS). Results: Eleven children and 139 adult patients were included $(n=150)$ in the study. In both populations, carbon monoxide poisoning (51\%) and iatrogenic gas embolism (33\%) were the two main causes of intubation and mechanical ventilation. The combination of midazolam and sufentanil was used in 85 (67\%) patients. All of the patients were given a bolus of a neuromuscular blocker during the hyperbaric session, despite the presence of ARDS in 35 patients. Patient-ventilator asynchrony was the most frequent side effect in 6 (5\%) patients and was often the consequence of suboptimal sedation. Mortality was higher in the group with ARDS (23\%).

Conclusions: Carbon monoxide poisoning and iatrogenic gas embolism are the two main diseases of the patients who required mechanical ventilation during hyperbaric oxygen therapy in this study. Mechanical ventilation is a safe method for patients during hyperbaric oxygen therapy. Sedation needs to be perfected to avoid patient-ventilator asynchrony.
\end{abstract}

(Int Marit Health 2017; 68, 1: 46-51)

Key words: mechanical ventilation, critically ill, hyperbaric oxygen therapy, hyperbaric chambers, ventilators, acute respiratory distress syndrome

\section{INTRODUCTION}

Hyperbaric oxygen therapy (HBOT) is the main treatment for many diseases, such as carbon monoxide (CO) poisoning, gas embolism or severe soft tissue infections $[1,2]$. The general principle of HBOT is to deliver oxygen $\left(\mathrm{O}_{2}\right)$ through the respiratory tract with an ambient pressure inside the chamber higher than atmospheric pressure. The therapeutic effects of HBOT result from two mechanisms, increasing the barometric pressure and the increasing $\mathrm{O}_{2}$ partial pressure [2].
The first effect is purely mechanical and results from Boyle-Mariotte's law, which evaluates the pressure $(\mathrm{P})$ and volume $(\mathrm{V})$ of a gas at a constant temperature (PV $=k$, $k$ is a constant value). This effect can reduce the volume of an intravascular gas bubble in case of an iatrogenic gas embolism (IGE) or decompression sickness (DCS).

The second effect of increasing the oxygen partial pressure in the blood is important for HBOT. Increasing the dissolved $\mathrm{O}_{2}$ content can supplement defects in blood $\mathrm{O}_{2}$ transport and accelerate denitrogenation. This also has 
bacteriostatic and bactericidal effects on anaerobic germs [3]. Finally, HBOT can lead to a hyperoxic vasoconstriction, can limit inflammatory oedema and should have a rheologic effect by increasing the deformability of red cells [4].

Hyperbaric oxygen therapy is delivered during one session or repetitive sessions, the duration and maximal pressure of which vary according to the specific protocols of different hyperbaric centres and the disease being treated. Hyperbaric chambers (HCs) are controlled and supervised by qualified staff (hyperbaric medicine and intensive care medicine). HCs depend on Intensive Care Units (ICU) or specialised emergency departments to care for critically ill patients who need mechanical ventilation (MV), inotropic support or thoracic drainage (chest tube). $\mathrm{MV}$ for critically ill patients is possible inside a $\mathrm{HC}$ under certain conditions [5]. Precautions should be carefully taken concerning the preparation of the patient, sedation and particularities based on material considerations because of the hyperoxic or explosive environment. Nevertheless, the literature lacks information on the epidemiology of ventilated patients benefiting from HBOT [6]. Consequently, we aimed to investigate the epidemiology of patients who require MV during HBOT sessions.

\section{MATERIALS AND METHODS \\ PURPOSE}

We aimed to investigate the epidemiology of patients who require MV during HBOT sessions.

\section{STUDY DESIGN AND PATIENTS}

A prospective observational study was performed in a University Hyperbaric Centre in France from January 1, 2005 to December 31, 2010. Garches is located in the Paris area and houses the only public $\mathrm{HC}$ for the entire region (12 million inhabitants). All of the consecutive intubated patients admitted for HBOT to our facility were prospectively enrolled during this 6-year period, regardless of age or disease. The hyperbaric therapy was almost always performed for acute injuries (DCS, CO poisoning, IGE, soft tissue infection) and chronic injuries (wounds, osteoradionecrosis).

\section{VENTILATION DEVICE USED}

For the duration of the study, we used the French ventilator $L A M A^{\circledR}(R C H$, France) which is a rudimentary ventilator. This ventilator has a CE certification. However, it is no longer distributed, and repairing the ventilator is becoming more difficult. Only two other ventilators have a CE certifications in Europe for MV under hyperbaric conditions, the Siaretron 1000 Iper $^{\circledR}$ (Siare, Italy) and Servo- ${ }^{\circledR}$ (Maquet, Sweden). The LAMA $^{\circledR}$ is a volumetric ventilator with a pneumatic logic controlling inspiratory flow at a constant level. This ventilator is preset in a range of 3 to $21 \mathrm{~L} / \mathrm{min}$ in $3 \mathrm{~L} / \mathrm{min}$

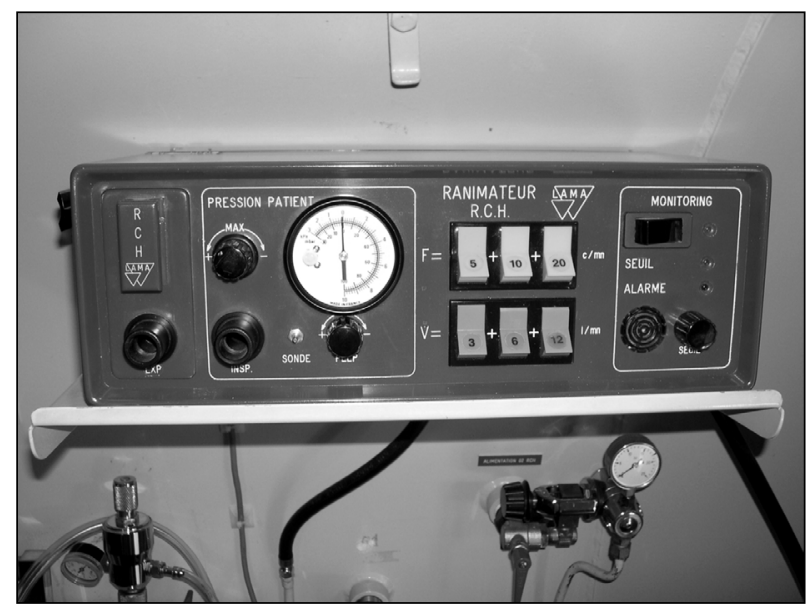

Figure 1. The $\mathrm{LAMA}^{\odot}$ ventilator

steps. Positive end-expiratory pressure (PEEP) is adjustable up to $10 \mathrm{cmH}_{2} \mathrm{O}$. The last possible setting is the breath rate, which is in the range of 5 to 35 breaths/min in 5 breaths/ /min steps. The oxygen concentration cannot be resolved; it is $100 \%$ by default (Fig. 1). Finally, this ventilator can operate only in the volume-controlled ventilation mode. It has an automatic compensation of tidal volume for hyperbaric conditions. Indeed, there is a normal increase of the gas density with compression during an HBOT session. Without this compensation mode, the user would have to change the tidal volume himself as the compression increased.

\section{COLLECTION OF DATA}

For every patient, we noted the sex, age, pathology, and positive inotropic support or MV required whenever needed. On a respiratory level, the relationship of the $\mathrm{PaO}_{2}(\mathrm{kPa})$ and $\mathrm{FiO}_{2}$, PEEP levels $\left(\mathrm{cmH}_{2} \mathrm{O}\right)$ and the presence or absence of acute respiratory distress syndrome (ARDS) were noted, according to the Berlin ARDS Definition [7]. Side effects have been reported. All of the data were collected with Exce ${ }^{\circledR}$ (Microsoft, Richmond, USA).

\section{STATISTICAL ANALYSIS}

All statistical analyses were performed using statistical software (Statplus, AnalystSoft). All of the continuous variables are expressed as the means with standard deviations. A Wilcoxon or Student's test was performed. All of the categorical variables are expressed as numbers with percentages and a $\chi^{2}$ test was used. A value of $p<0.05$ was considered statistically significant for all of the tests.

\section{RESULTS}

From 1 January 2005 to 31 December 2010, 1024 patients (for 1367 HBOT sessions) were admitted for HBOT, of whom 150 (14.65\%) were mechanically ventilated (Fig. 2). 


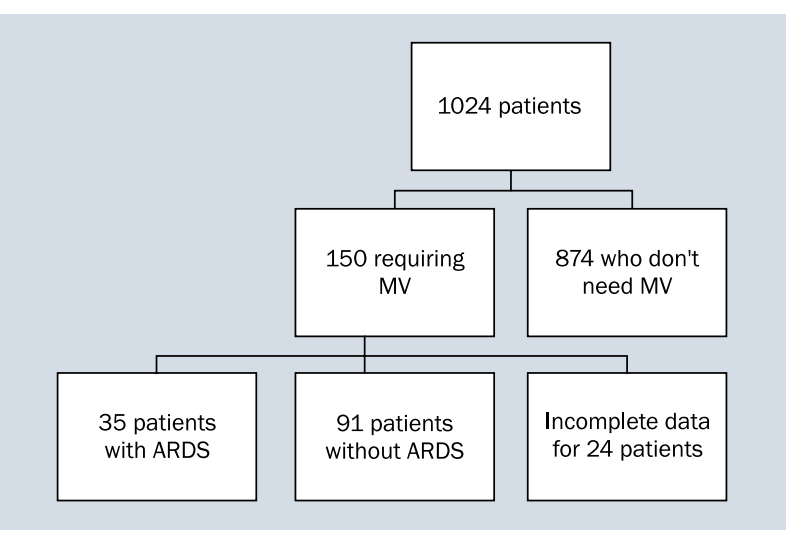

Figure 2. Repartition of patients at admission in the hyperbaric unit; ARDS - acute respiratory distress syndrome; MV - mechanical ventilation
The sex ratio was 1.72 (95 men), and the ages were ranged between 18 days of life and 94 (51 \pm 21.9$)$ years old. We divided the patients into three groups based on whether they required MV or not. Among the patients who required MV, we noted whether ARDS was present or not.

Both Tables 1 and 2 show the baseline characteristics and clinical data of the patients. Severe carbon monoxide poisoning and IGE accounted for the majority of diagnoses leading to MV. However, patients with soft tissue infection are rarer but they are often critically ill and require MV too. Positive inotropic support was required in $28 \%$ of the patients because of shock. ARDS was present in 35 patients who were ventilated with the highest PEEP levels available in the $\mathrm{HC}$ (mean PEEP, $8 \mathrm{cmH}_{2} \mathrm{O}$ ).

Table 1. Base-line characteristics

\begin{tabular}{llll}
\hline Characteristics of patients & MV with ARDS $(\mathbf{n}=\mathbf{3 5})$ & MV without ARDS $(\mathbf{n}=\mathbf{9 1})$ & P \\
\hline Male/female sex-ratio & 2.88 & 1.33 & 0.12 \\
Age & $50[36 ; 65.5]$ & $59[40.5 ; 70.5]$ & 0.22 \\
Number of sessions & $1[1 ; 1]$ & $1[1 ; 1]$ & 0.69 \\
CO poisoning & $23(65.71 \%)$ & $43(47.25 \%)$ & 0.097 \\
IGE & $7(20 \%)$ & $35(38.46 \%)$ & 0.079 \\
Soft tissue infection & $5(14.29 \%)$ & $12(13.19 \%)$ & 1.00 \\
$\mathrm{H}_{2}$ S poisoning & $0(0 \%)$ & $0(0 \%)$ & - \\
ATPI & $0(0 \%)$ & $0(0 \%)$ & - \\
DCS & $0(0 \%)$ & $1(1.09 \%)$ & -
\end{tabular}

ARDS - acute respiratory distress syndrome; ATPI - acute traumatic peripheral ischaemia; CO - carbon monoxide; DCS - decompression sickness; IGE - iatrogenic gas embolism; MV - mechanical ventilation; $\mathrm{H}_{2} \mathrm{~S}$ - hydrogen sulphide

Table 2. Clinical status of patients

\begin{tabular}{|c|c|c|c|}
\hline Clinical status of patients & ARDS+ $(n=35)$ & ARDS- $(n=91)$ & $\mathbf{P}$ \\
\hline Norepinephrine & $6(17.14 \%)$ & $25(27.47 \%)$ & - \\
\hline Epinephrine & $1(2.85 \%)$ & $3(3.29 \%)$ & - \\
\hline Dopamine & $1(2.85 \%)$ & $2(2.19 \%)$ & - \\
\hline Norepinephrine/dobutamine & $0(0 \%)$ & $1(1.09 \%)$ & - \\
\hline Sedation with $\mathrm{M}$ alone & $4(11.43 \%)$ & $8(8.79 \%)$ & - \\
\hline Sedation with $\mathrm{M} / \mathrm{S}$ & $25(71.43 \%)$ & $60(65.93 \%)$ & - \\
\hline Sedation with $\mathrm{M} / \mathrm{F}$ & $4(11.43 \%)$ & $11(12.09 \%)$ & - \\
\hline Sedation with P/S & $1(2.86 \%)$ & $4(4.4 \%)$ & - \\
\hline Sedation with $\mathrm{P}$ alone & $0(0 \%)$ & $4(4.4 \%)$ & - \\
\hline Sedation with $\mathrm{M} / \mathrm{S} / \mathrm{K}$ & $1(2.86 \%)$ & $0(0 \%)$ & - \\
\hline Sedation with VP or $\mathrm{N}$ & $0(0 \%)$ & $1(1.1 \%)$ & - \\
\hline PEEP $\left[\mathrm{cmH}_{2} \mathrm{O}\right]$ & $8[5 ; 10]$ & $4[0 ; 5]$ & $<0.0001$ \\
\hline $\mathrm{PaO}_{2} / \mathrm{FiO}_{2}[\mathrm{kPa}]$ & $13.5[10.25 ; 22.1]$ & $35.6[28.5 ; 48.2]$ & $<0.0001$ \\
\hline
\end{tabular}


Table 3. Side effects

\begin{tabular}{llll}
\hline Side effects/Outcome & MV with ARDS (n = 35) & MV without ARDS (n = 91) & P \\
\hline Side effects & $2(5.71 \%)$ & $13(14.29 \%)$ & 0.31 \\
Major side effects & $1(2.86 \%)$ & $6(6.59 \%)$ & - \\
Seizures (2 IGE) & $0(0 \%)$ & $2(2.2 \%)$ & - \\
CPA (IGE, CO) & $1(2.86 \%)$ & $1(1.1 \%)$ & - \\
Shock (2 CO, 1STI) & $0(0 \%)$ & $3(3.3 \%)$ & - \\
Minor side effects & $1(2.86 \%)$ & $5(5.49 \%)$ & - \\
$\quad$ Dyssynchrony (3 CO, 2 IGE, 1STI) & $1(2.86 \%)$ & $5(5.49 \%)$ & - \\
$\quad$ Middle-ear barotrauma & $0(0 \%)$ & $0(0 \%)$ & 0.041 \\
Died in ICU & $8(22.86 \%)$ & $7(7.69 \%)$ & 0.068
\end{tabular}

ARDS - acute respiratory distress syndrome; CO - carbon monoxide poisoning; CPA - cardiopulmonary arrest; ICU - Intensive Care Units; IGE - iatrogenic gas embolism; $\mathrm{MV}$ - mechanical ventilation; STI - soft tissue infection

The complications data are shown in Table 3. First, $6(4.8 \%)$ patients presented with minor side effects, such as agitation and hallucinations, probably due to ketamine and inadequate sedation. The minor side effects were patient-ventilator asynchrony because of suboptimal sedation and environmental stress. Indeed, all of the patients, regardless of age, had been more or less sedated. Two patients presented with the major side effects of cardiopulmonary arrests (1.6\%), 2 (1.6\%) presented with epileptic seizures and $3(2.4 \%)$ presented with severe shocks despite the use of inotropic drugs. The mortality in the ICU reached $23 \%$ in the ARDS group.

\section{DISCUSSION}

The main interest of our work was to present, for the first time and for a large panel of patients, the epidemiology of $\mathrm{MV}$ for patients requiring hyperbaric oxygenation treatment. Until this study, we did not know precisely why or how children or adults were ventilated with HBOT.

\section{WHICH PATIENTS NEED TO BE VENTILATED IN HYPERBARIC CHAMBERS?}

Some patients need MV after certain injuries. In a few experimental cases, MV is the main treatment for conditions such as iatrogenic gas embolism [8]. However, more often, $\mathrm{MV}$ is one part of a treatment plan, such as positive inotropic support or antibiotic therapy, for soft tissue infections or $\mathrm{CO}$ poisoning. Consequently, MV has to be performed before, during, and after an HBOT session. For the Undersea and Hyperbaric Medical Society (UHMS) and the European Committee for Hyperbaric Medicine (ECHM), HBOT is approved for IGE, DCS, carbon monoxide or cyanide poisoning, smoke inhalation, necrotizing soft tissue infections, crush injuries, compartment syndromes, acute traumatic peripheral ischaemia, enhancement of healing for selected wounds, refractory osteomyelitis and compromised skin flaps or grafts $[1,9]$. In this work, we used HBOT for severe diseases, such as IGE, CO poisoning and necrotizing soft tissue infection. We have also used HBOT in 2 cases of severe $\mathrm{H}_{2} \mathrm{~S}$ poisoning in children despite a lack of scientific evidence.

\section{PATIENT'S PREPARATION}

Because of the variations of atmospheric pressure (Boyle-Mariotte law's stated in the mid - $1600 \mathrm{~s}$ that the absolute pressure and volume of a given mass of gas are inversely proportional at a constant temperature) during an HBOT session, saline is used to inflate the endotracheal tube's (ETT) cuff for intubated patients. We routinely inject saline in the cuff to replace air before compression. Contrary to air or gases, liquids are not compressible during pressure variations, such as during increases (HBOT) or decreases in atmospheric pressure (flying above sea level). Based on our experience, we prefer saline to fill the cuffs, but others liquids can be used. Although saline should not be used to fill balloons of urinary catheters (crystallisation and valve malfunction), its use for ETT's cuff filling is safe for a few hours. Sterile water should be used cautiously because of its irritating effect laryngotracheally in the case of a cuff rupture. We reported some bronchospasms in such cases [10]. Instead of performing a chest X-ray to look for a pneumothorax before entering a $\mathrm{HC}$, physician should perform a more relevant, non-invasive chest sonography to detect a pneumothorax [11-13].

\section{SEDATION DURING HBOT}

Hyperoxia leads to peripheral vasoconstriction. Consequently, under hyperbaric conditions, parenteral drugs absorption may be different from standard conditions. An intravenous infusion is the best way to administer drugs in 
a HC. Syringe pumps are available for this specific use [14]. Sedation and analgesia of the intubated patient has to be optimal because of the many constraints that occur during an HBOT session: intra or interhospital transport, shaft handlings, noise, temperature variations (temperature increases during the compression phase, but falls during decompression), otalgia, ventilator tolerance, and postoperative pain surgery (necrotizing soft tissue infection). Usual sedation combining an opioid (fentanyl or sufentanil) with a hypnotic like midazolam or propofol is well adapted for hyperbaric conditions. In this study, 107 $(84 \%)$ patients received this type of sedation. Although all of the patients received sedation, 18 (14\%) were probably wrongly sedated using midazolam, propofol or an antiepileptic drug infused alone. Ketamine, antidepressants and neuroleptics were not used for continuous sedation in the hyperbaric environment. Only 2 children received ketamine during the study period. Halogen gases are avoided in this environment because they depend on a specific vaporizator that may lead to an electrical arc. Finally, neuromuscular blocker use is possible in association with sufficient sedation with the same advantages and disadvantages associated with its use in the ICU [15]. There are neither proven pharmacokinetic nor pharmacodynamic effects due to high pressure until $608 \mathrm{kPa}$ (50 msw depth) for anaesthesia drugs [16].

\section{CARE OF INTUBATED PATIENT}

The compression of the $\mathrm{HC}$ and the solitary confinement require attentive supervision of the patient. In the case of a quick ascent, it is almost impossible to take a patient out of the chamber in less than $10 \mathrm{~min}$ because of the risk of DCS for both the patient and caregiver. Consequently, patients should be monitored, and their arterial pressure, heart beat and oxygen saturation should be frequently supervised. Moreover, patients seemed to be more and more seriously ill in our facility. MV and positive inotropic support have increased from $17 \%$ to $29 \%$ and from $7 \%$ to 19\%, respectively, between 2005 and 2010 . The head nurse should look for an asymmetric thoracic expansion during breathing and an absence of subcutaneous emphysema appearance because attentive lung auscultation is unrealistic with such background noise. To limit the hypercapnia risk for the patient, the tidal volume should be checked with the aid of calibrated spirometry or capnography that decreases with compression and is correlated to the $\mathrm{P}_{\mathrm{TC}} \mathrm{CO}_{2}$ and $\mathrm{PaCO}_{2}[17,18]$. Neither Bis-spectral index monitoring nor clinical sedation-agitation scales have yet been evaluated under hyperbaric conditions [19]. After an HBOT session and upon return to the ICU, an ETT cuff will be reinflated with air to avoid saline crystallisation and the risk of cuff rupture.

\section{COMPLICATIONS AND SIDE EFFECTS OF HBOT}

The main adverse-effects of HBOT are barotraumas and claustrophobia. Claustrophobia is possible in awaked patients, especially in monoplace chambers that are forbidden and not used in France. However, it is still possible to propose sedation (benzodiazepine or neuroleptics) for these patients. Barotrauma is not uncommon, and is a concern in the middle ear (MEB), teeth, sinuses and lungs. Contrary to accepted ideas, a recent French study questioned the use of MV as a risk factor for an MEB [20]. MEB onset seems to depend on many parameters, such as the compression speed. There is a systematic evaluation for a pneumothorax before compression, but a classical chest X-ray is inadequate to evaluate for the presence of a small or anterior pneumothorax with certainty. We have known for a few years that chest ultrasonography and tomodensitometry are both better than a chest X-ray [11, 12]. Finally, inhaling high concentrations of oxygen under pressure may lead to a seizure (cerebral oxygen toxicity). The Paul Bert effect explains that oxygen may lead to a seizure when the oxygen partial pressure $\left(\mathrm{ppO}_{2}\right)$ is up to $180 \mathrm{kPa}$ [21]. We observed 2 seizures during this study in IGE victims, but none in the other patients. However, IGE itself can lead to a seizure. Additionally, our HBOT protocol proposed a compression to 3.8 absolute atmospheres, leading to a $\mathrm{ppO}_{2}$ that reached $380 \mathrm{kPa}$. In our work, the mortality in the ARDS group is $23 \%$ which is not higher from noticed rates $(11 \%$ to $87 \%)$ in the general literature, including all aetiologies [22].

\section{CONCLUSIONS}

Mechanical ventilation is a safe method for patients during HBOT and can be used routinely. In our experience, iatrogenic gas embolism, carbon monoxide poisoning and soft necrotizing tissue infection are the main injuries leading to ventilation. Patients in our hyperbaric centre seem to be more and more seriously ill. This demonstrates the necessary closeness between hyperbaric chambers and intensive care units.

\section{REFERENCES}

1. Hampson NB. ed. Hyperbaric oxygen therapy: 1999 committee report. Kensington MD, Undersea and Hyperbaric Medical Society 1999.

2. Tibbles PM, Edelsberg JS. Hyperbaric-oxygen therapy. N Engl J Med. 1996; 334(25): 1642-1648, doi: 10.1056/NEJM199606203342506, indexed in Pubmed: 8628361.

3. Park MK, Myers RA, Marzella L. Oxygen tensions and infections: modulation of microbial growth, activity of antimicrobial agents, and immunologic responses. Clin Infect Dis. 1992; 14(3): 720-740, indexed in Pubmed: 1562664.

4. Mathieu D, Cojet J, Vinckier F, et al. Red blood cell deformability and hyperbaric oxygen. Med Subaquatique Hyperbar. 1984; 3: 100-104.

5. Mathieu D, Ratzenhofer-Komenda B, Kot J. Hyperbaric oxygen therapy for intensive care patients: position statement by the European 
Committee for Hyperbaric Medicine. Diving Hyperb Med. 2015; 45(1): 42-46, indexed in Pubmed: 25964038.

6. Keenan HT, Bratton SL, Norkool DM, et al. Delivery of hyperbaric oxygen therapy to critically ill, mechanically ventilated children. J Crit Care. 1998; 13(1): 7-12, indexed in Pubmed: 9556121.

7. Ranieri VM, Rubenfeld GD, Thompson BT, et al. ARDS Definition Task Force. Acute respiratory distress syndrome: the Berlin Definition. JAMA. 2012; 307(23): 2526-2533, doi: 10.1001/jama.2012.5669, indexed in Pubmed: 22797452.

8. Annane D, Troché G, Delisle F, et al. Effects of mechanical ventilation with normobaric oxygen therapy on the rate of air removal from cerebral arteries. Crit Care Med. 1994; 22(5): 851-857, indexed in Pubmed: 8181296.

9. First European Consensus Conference on Hyperbaric Medicine, Lille (France). http://www.medsubhyp.com/site/conferences_consensus.htm (1994).

10. Bessereau J, Coulange M, Jacquin L, et al. Endotracheal tube intracuff pressure during helicopter transport. Ann Emerg Med. 2010; 56(5): 583-4; author reply 584, doi: 10.1016/j.annemergmed.2010.04.031, indexed in Pubmed: 21036300.

11. Lichtenstein DA. Ultrasound in the management of thoracic disease. Crit Care Med. 2007; 35(5 Suppl): S250-S261, doi:10.1097/01.CCM.0000260674.60761.85, indexed in Pubmed: 17446785 .

12. Ding Wu, Shen $Y$, Yang J, et al. Diagnosis of pneumothorax by radiography and ultrasonography: a meta-analysis. Chest. 2011; 140(4): 859-866, doi:10.1378/chest.10-2946, indexed in Pubmed: 21546439.

13. Xirouchaki N, Magkanas E, Vaporidi K, et al. Lung ultrasound in critically ill patients: comparison with bedside chest radiography.
Intensive Care Med. 2011; 37(9): 1488-1493, doi: 10.1007/ s00134-011-2317-y, indexed in Pubmed: 21809107.

14. Kindwall EP. The use of drugs under pressure. In: Kindwall EP, Wheelan HT editors. Hyerbaric Medicine Practice, 2nd ed, Best Publishing Co, Flagstaff; 2004. p. : 323-338.

15. Claudius C, Garvey LH, Viby-Mogensen J. The undesirable effects of neuromuscular blocking drugs. Anaesthesia. 2009; 64 Suppl 1: 10-21, doi:10.1111/j.1365-2044.2008.05866.x, indexed in Pubmed: 19222427.

16. Moon RE, Camporesi EM. Clinical care in extreme environments: at high and low pressure and in space. In. Miller RD, Churchill Livingstone Edition. Miller's anesthesia, 7th ed; 2009, Chapter 80.

17. Blanch PB, Desautels DA, Gallagher TJ. Deviations of function of mechanical ventilators function during hyperbaric compression. Respir Care. 1991; 36: 803-814.

18. Eskelson MI, Weaver LK, Greenway L. End-tidal CO2 monitoring within the monoplace hyperbaric chamber. Undersea Biomed Res. 1989; 16(Suppl): A13.

19. Barr J, Fraser G, Puntillo K, et al. Clinical practice guidelines for the management of pain, agitation, and delirium in adult patients in the intensive care unit. Crit Care Med. 2013; 41(1): 263-306, doi: 10.1097/ccm.0b013e3182783b72.

20. Bessereau J, Tabah A, Genotelle N, et al. Middle-ear barotrauma after hyperbaric oxygen therapy. Undersea Hyperb Med. 2010; 37(4): 203-208, indexed in Pubmed: 20737927.

21. Bitterman N. CNS oxygen toxicity. Undersea Hyperb Med. 2004; 31(1): 63-72.

22. Máca J, Jor 0 , Holub $\mathrm{M}$, et al. Past and present ARDS mortality rates: a systematic review. Respir Care. 2017; 62(1): 113-122, doi:10.4187/respcare.04716, indexed in Pubmed: 27803355. 